Glückwunschbotschaft der DDG

\title{
Congratulations of the DDG
}

H. Gollnick
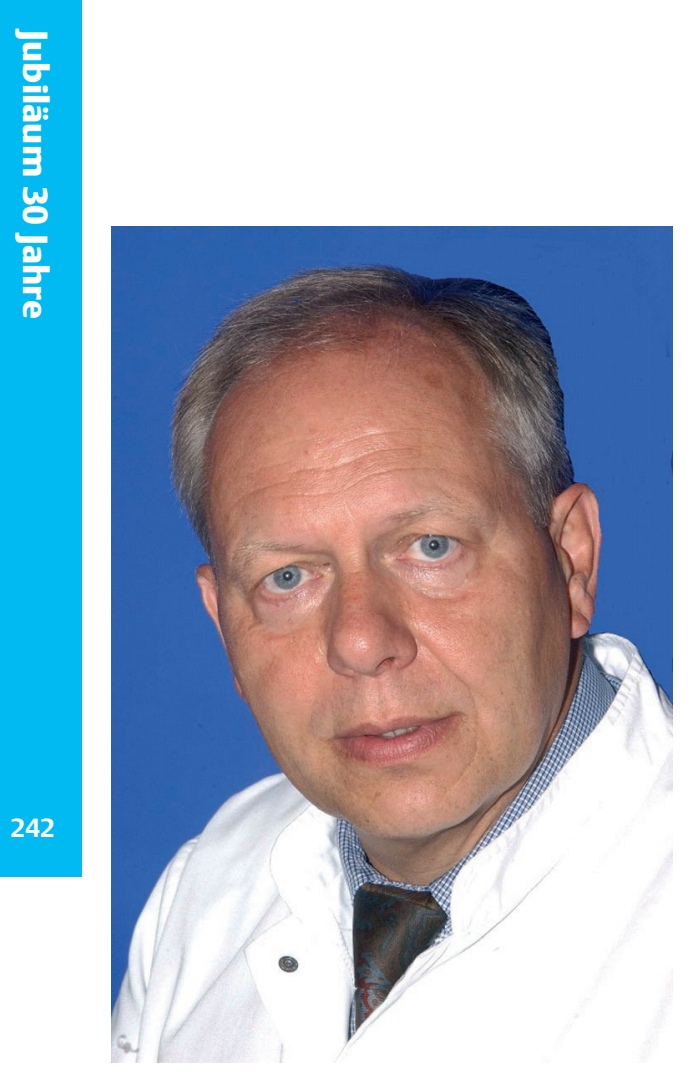

Im Namen des Vorstandes der Deutschen Dermatologischen Gesellschaft erlaube ich mir der Schriftleitung und den Herausgebern sowie dem Thieme-Verlag zum Anlass des 30-jährigen Jubiläums der „Aktuellen Dermatologie“ sehr herzlich zu gratulieren. Die Zeitschrift „Aktuelle Dermatologie“ hat es verstanden, über drei Jahrzehnte eine kontinuierliche und optimale verlegerische Leistung in Hinsicht auf Fort- und Weiterbildungsartikel in Deutschland zu zeigen. Über die Jahre ist es der Zeitschrift gelungen, eine stete Kontinuität in der Qualität der Beiträge auszuweisen. Vor allem in den letzten Jahren hat das Bild der Zeitschrift durch geschliffene Editorials, die Seite „Aktuell“ oder das Voranstellen von Kommentaren deutlich gewonnen. „Aktuelle Dermatologie" hat nie den Anspruch erhoben eine Zeitschrift mit wissenschaftlicher Ausrichtung zu sein, jedoch sind die klinischen Originalarbeiten immer aktuell und interessant für die in der Praxis tätigen Kolleginnen und Kollegen sowie junge Assistentinnen und Assistenten gewesen und werden es, getragen von der aktiven Herausgebermannschaft, auch wohl weiterhin sein. Der Verlag garantiert stets eine pünktliche Herstellung, gute Druckqualität und Layout, so dass die „Aktuelle Dermatologie“ als die kleine Schwester der Familie der drei deutschen klinischen Fachzeitschriften im Fachgebiet der Dermato-Venerologie und ihrer Subspezialitäten auch weiterhin ihren festen Platz hat.

Alles Gute für die Zukunft und weiterhin viel Erfolg.

Prof. Dr. H. Gollnick

Präsident der DDG 